\title{
Characterization of Selective TRPM8 Ligands and their Structure Activity Response (S.A.R) Relationship
}

\author{
Muhammad Azhar Sherkheli, ${ }^{1,2,3}$ Angela K. Vogt-Eisele²; Daniel Bura, ${ }^{2}$; Leopoldo R. Beltrán Márques², Günter \\ Gisselmann ${ }^{2}$ and Hanns Hatt ${ }^{2}$ \\ ${ }^{1}$ National Center of Excellence in Molecular Biology, University of The Punjab, Lahore, Pakistan. \\ ${ }^{2}$ Lehrstuhl für Zellphysiologie, Ruhr-University-Bochum, Bochum 44780, Germany . \\ ${ }^{3}$ IMPRS-CB; c/o Max-Plank Institute of Molecular Physiology, Otto-Hahn-Str 11, 44227 Dortmund, Germany.
}

Received, January 31, 2010; Revised, July 13, 2010; Accepted, July 21, 2010; Published, July 22, 2010.

\begin{abstract}
Purpose. Transient receptor potential melastatin-8 (TRPM8) is an ion channel expressed extensively in sensory nerves, human prostate and overexpressed in a variety of cancers including prostate, breast, lung, colon and skin melanomas. It is activated by innoxious cooling and chemical stimuli. TRPM8 activation by cooling or chemical agonists is reported to induce profound analgesia in neuropathic pain conditions. Known TRPM8 agonists like menthol and icilin cross-activate other thermo-TRP channels like TRPV3 and TRPA1 and mutually inhibit TRPM8. This limits the usefulness of menthol and icilin as TRPM8 ligands. Consequently, the identification of selective and potent ligands for TRPM8 is of high relevance both in basic research and for therapeutic applications. In the present investigation, a group of menthol derivatives was characterized. These ligands are selective and potent agonists of TRPM8. Interestingly they do not activate other thermo-TRPs like TRPA1, TRPV1, TRPV2, TRPV3 and TRPV4. These ion channels are also nociceptors and target of many inflammatory mediators. Methods. Investigations were performed in a recombinant system: Xenopus oocytes microinjected with cRNA of gene of interest were superfused with the test substances after initial responses of known standard agonists. Evoked currents were measured by two-electrode voltage clamp technique. Results. The newly characterized ligands possess an up to six-fold higher potency $\left(\mathrm{EC}_{50}\right.$ in low $\left.\mu \mathrm{M}\right)$ and an up to two-fold increase in efficacy compared to the parent compound menthol. In addition, it is found that chemical derivatives of menthol like CPS-368, CPS-369, CPS-125, WS-5 and WS-12 are the most selective ligands for TRPM8. The enhanced activity and selectivity seems to be conferred by hexacyclic ring structure present in all ligands as substances like WS-23 which lack this functional group activate TRPM8 with much lower potency $\left(\mathrm{EC}_{50}\right.$ in $\left.\mathrm{mM}\right)$ and those with pentacyclcic ring structure (furanone compounds) are totally inactive. Conclusion. The new substances activate TRPM8 with a higher potency, efficacy and specificity than menthol and will thus be of importance for the development of pharmacological agents suitable for treatment and diagnosis of certain cancers and as analgesics.
\end{abstract}

\section{INTRODUCTION}

The transient receptor potential (TRP) ion channel family comprises about 28 mammalian cation channels. They are involved in a wide range of physiological and patho-physiological processes including taste, thermosensation, pain, fertilization, cell cycle regulation and stem cell differentiations. TRP ion channels present a novel mechanism for controlling $\mathrm{Ca}^{2+}$ transients in human neurons and offer a target for regulating proliferation and neurite outgrowth, particularly for engineering stem cells for therapeutic transplantation $(1,2)$. Due to their relatively recent discovery, their widespread expression patterns and the diversity of their gating stimuli, knowledge about pharmacology and physiological functions of the members of this family is rapidly growing and opening new vistas of understandings about sensory cellular physiology (3-5). Six TRPs (TRPV1, TRPV2, TRPV3, TRPV4, TRPM8 and TRPA1) have been shown to be expressed in primary afferent nociceptors (pain-sensing neurons) where they act as transducers for thermal, chemical and mechanical stimuli (6). TRPM8 belongs to the thermosensitive members of this superfamily (thermo-TRPs) and activates upon innocuous cooling (7).

Corresponding Author: Ast. Prof. Dr. Muhammad Azhar Sherkheli, National Center of Excellence in Molecular Biology, University of The Punjab, Lahore, Pakistan, E-mail: Azhar.Sherkheli@daad-alumni.de 
Recently, it was reported that mice with a disruption in the TRPM8 gene exhibit serious deficiencies in a range of cold responses (8-10). These results suggested that TRPM8 is the predominant detector of cold temperatures in in vivo. In addition, TRPM8 can be activated by chemical agonists like menthol, eucalyptol or icilin which therefore induce a feeling of coolness (7) without actually lowering skin temperature.

TRPs are emerging as promising targets for the treatment of diverse pathological conditions like neuropathic pain (11), pruritus $(12,13)$, or inflammatory hyperalgesia $(14,15)$. While moderate cooling has a long history in pain relief (16), the mechanism(s) underlying such analgesia remains elusive. Menthol is capable of producing sensation of cooling and this is attributed to its activation of TRPM8. Recently, it was shown that TRPM8 mediates analgesia caused by mild cooling and cooling agents such as menthol and icilin by inhibiting nociceptive input to the central nervous system (15).

Menthol also modulates the responses of TRPV3 and TRPA1 (17-19). This makes it a non selective ligand for TRPM8. TRPV3 and TRPA1 ion channels have been implicated in nociception, inflammation, pruritus and skin itch $(13,20,21)$. This non selectivity in action of menthol is suggested (17-19) to be the underpinning cause for burning and itching effects in humans (22). Another best known TRPM8 ligand is icilin, which has been projected as 'super cooling' agent (23). In addition to the modulation of TRPM8 activity, icilin also activates TRPA1 ion channels, the later is well established nociceptor (21). Recently it was reported that icilin also inhibits TRPM8 (24). Consequently, the therapeutic utility of icilin as TRPM8 ligand is limited. TRPM8 also plays a role in prostate cancer (25) and human skin melanomas (26). In prostate cancer TRPM8 is now a tumour marker, and has a significant therapeutic potential in diagnosis and therapy of bladder cancer (27). Therefore, identification for potent and selective TRPM8 ligands is of direct clinical relevance.

Chemicals with menthol-like cooling actions were first described by Watson et al. (28). Two $N$ alkyl-cycloalkyl- and $N$-alkyl-alkyl carboxyamides, WS-3 and WS-23, are currently approved for use in toiletries and cosmetics. WS3 and WS-23 were identified as cooling agents based on their effects on the human tongue and later found to be TRPM8 agonists. WS-23 is less active than menthol (29) and it is not known whether WS-3 acts only on TRPM8 or also activates TRPV3 and TRPA1 like menthol. Recently, Ermann has called attention to WS-5, an $N$-alkylcarbonyl-amino acid ester formed by the conjugation of p-methane to glycine ethyl ester, as an active cooling agent for the oral cavity (30). As several recent studies report a significant overlap in the pharmacological profile of different thermo-sensitive TRP channels $(17,18,31,32)$, one of the greater challenges in the development of potent new agonists lies in their specificity. Given the broad tissue distribution of most thermo-TRPs and the limited knowledge about their function, activation of additional channels bears the risk of serious side effects.

In this context, specific and potent new TRPM8 agonists are of great importance as potential agents for the relief of injury-related or chronic neuropathic pain, in prostate cancer as makers or in skin melanomas as novel therapeutic-agents. While a number of TRPM8 agonists are characterized (29) their suitability for clinical applications remains uncertain due to lack of selectivity and specificity data. In a previous study we reported selectivity of WS-12 for TRPM8 (18). Here we report additional four new selective TRPM8 agonists that are more potent than the parent compound menthol and do not activate any other members of the TRP family like TRPV1-4 and TRPA1. In addition we show structure activity relationship of TRPM8 ligands. We hypothesize that all most all potent ligands for TRPM8 require hexacyclic ring(s) and bulky $N$ alkylcarbonyl side-chains for enhanced potency and selectivity.

\section{MATERIAL AND METHODS}

\section{Expression vectors for TRP channels}

Expression vectors for the TRP channels hTRPV1, rTRPV2, mTRPV3, rTRPV4, hTRPA1 and mTRPM8 ( $h$, human, $\mathrm{m}$, mouse, $\mathrm{r}$, rat) were generous gifts from D. Julius, M. Schäfer and H.J. Behrendt. For the efficient expression in Xenopus oocytes, cDNA inserts of hTRPV1, rTRPV2, mTRPV3 and rTRPV4 were subcloned by a PCRbased standard method into the oocyte expression vector pSGEM (33).

\section{Synthesis and injection of TRP cRNA}

The generation of cRNA was performed by standard methods as described elsewhere $(18,34)$. In brief plasmids, containing cloned cDNA as a template for in vitro transcription, were linearized downstream of the end of the cDNA. Capped RNAs were synthesized in the presence of 
capping analogue $\mathrm{m}^{7} \mathrm{G}\left(5^{\prime}\right) \mathrm{ppp}\left(5^{\prime}\right) \mathrm{G}$ using the AmpliCap- $\mathrm{T}^{7}$ MessageMaker Kit (Epicentre, Madison, WI). RNA was ethanol-precipitated and redissolved in RNase-free water to give a final concentration of $1 \mu \mathrm{g} / \mu \mathrm{l}$. Ovarian lobes were obtained from mature female Xenopus laevis anesthetized by immersion in $0.15 \%$ 3aminobenzoic acid ethyl ester. Ovarian tissue was removed and placed in Barth's solution $(88 \mathrm{mM}$ $\mathrm{NaCl}, 1 \mathrm{mM} \mathrm{KCl}, 0.82 \mathrm{mM} \mathrm{MgSO} 4,0.33 \mathrm{mM}$ $\mathrm{Ca}\left(\mathrm{NO}_{3}\right)_{2}, 0.41 \mathrm{mM} \mathrm{CaCl}_{2}, 2.4 \mathrm{mM} \mathrm{NaHCO} 3,5$ $\mathrm{mM}$ HEPES, $100 \mathrm{U} / \mathrm{ml}$ penicillin, $50 \mu \mathrm{g} / \mathrm{ml}$ streptomycin; $\mathrm{pH}$ 7.4). After treatment of the ovarian tissue with collagenase (Type $\mathrm{I}, 4 \mathrm{mg} / \mathrm{ml}$ in $\mathrm{Ca}^{2+}$-free Barth's solution) for two hours at room temperature, the oocytes were incubated overnight in fresh Barth's solution $\left(15^{\circ} \mathrm{C}\right)$. After $24 \mathrm{~h}$, mature healthy oocytes (stage V to VI) were selected for cytoplasmic injection of cRNA (about $50 \mathrm{nl}$ per oocyte; approximate cRNA concentration $1 \mu \mathrm{g} / \mu \mathrm{l}$ ) with a sharp pipette using a pressure injector (npi PDES 04T, Tamm, Germany). Afterwards, injected oocytes were placed in ND-96 $(96 \mathrm{mM} \mathrm{NaCl}, 2 \mathrm{mM} \mathrm{KCl}, 1.8$ $\mathrm{mM} \mathrm{CaCl} 2,1 \mathrm{mM} \mathrm{MgCl}, 5 \mathrm{mM}$ HEPES, 100 units $/ \mathrm{ml}$ penicillin $\mathrm{G}, \quad 50 \mu \mathrm{g} / \mathrm{ml}$ streptomycin sulphate and $25 \mu \mathrm{g} / \mathrm{ml}$ amphotericin $\mathrm{B} ; \mathrm{pH}$ 7.4) solution and incubated at $16-18^{\circ} \mathrm{C}$. Oocytes were tested for functional expression of TRP-channels after 3 to 5 days.

\section{Electrophysiological recordings in Oocytes}

Two-electrode voltage-clamp recording was used to obtain current responses to applied substances. Agonists and antagonists were diluted to the concentrations indicated with calcium-containing (115 mM NaCl, $2.5 \mathrm{mM} \mathrm{KCl}, 1.8 \mathrm{mM} \mathrm{CaCl}_{2}, 200$ $\mu \mathrm{M}$ flufenamic acid, $10 \mathrm{mM}$ HEPES, $\mathrm{pH}$ 7.4) or calcium-free $(115 \mathrm{mM} \mathrm{NaCl}, 2.5 \mathrm{mM} \mathrm{KCl}, 10$ $\mathrm{mM}$ HEPES, $\mathrm{pH}$ 7.4) Xenopus-Ringer. Flufenamic acid was added to block $\mathrm{Ca}^{2+}$ activated chloride channels. Agonists were applied by means of a multibarrel single tip superfusion device or by manual application. Application time was usually 10 seconds. Electrodes were pulled from borosilicate glass using a Kopf vertical pipette puller. Electrodes were backfilled with $3 \mathrm{M} \mathrm{KCl}$. Holding potential was $-60 \mathrm{mV}$. Membrane potential was controlled and current signals were recorded with a twoelectrode voltage-clamp amplifier (TURBO TEC03, npi, Tamm, Germany) and the PCLAMP software (Molecular Devices, Sunnyvale, CA). Experiments were performed at room temperature $\left(\sim 23^{\circ} \mathrm{C}\right)$.

\section{REAGENTS}

WS-5, all CPS-substances and icilin were gifts from Prof. Dr. Edward. T. Wei of the University of California, Berkeley, U.S.A. All other chemicals were purchased from Sigma-Aldrich.

\section{DATA ANALYSIS}

All data were analysed for statistical significance by using student's paired-t test (Microsoft Excel or Sigmastat software version 2.03). Statistical probability (p) is expressed as *p $<0.05, * * p<$ 0.01 and $* * * p<0.001$ to indicate various levels of statistical significance. Curve fitting was done by Hill equation using SigmaPlot V8.0 (Systat Software, San Jose, CA). $\mathrm{EC}_{50}$ represents means of 4-7 individual independent experiments under similar conditions. All values are expressed as mean \pm SEM.

\section{RESULTS}

\section{Activation of TRPM8}

TRPM8 was expressed in the Xenopus oocyte system and channel activity assayed by twoelectrode voltage-clamp. We addressed the question whether the new substances (menthol derivatives and furanone compounds) activate TRPM8 and sought to determine their potency and efficacy in comparison to icilin and menthol. WS-5 was tested for activation of TRPM8 expressed in Xenopus oocytes (Figure 1 and table $1)$. We found that WS-5 robustly activates TRPM8. The $\mathrm{EC}_{50}$ was determined to be $26 \pm 7$ $\mu \mathrm{M}$ and thus almost one order of magnitude lower than that of menthol, which in our system was $196 \pm 22 \mu \mathrm{M}$. However, WS-5 was still roughly 3 times less potent than the synthetic cooling agent icilin, which in our hands had an $\mathrm{EC}_{50}$ of $7 \pm 3 \mu \mathrm{M}$. Two related amino acid conjugates namely the Dalanine-O-ethyl conjugate coded as CPS-369 and the D-alanine-O-methyl conjugate coded as CPS368 and sulfadiazine conjugate CPS-125 were tested. All compounds robustly activated TRPM8. CPS-125 showed affinities similar to WS-5 (32 \pm 6 $\mu \mathrm{M})$. CPS-369 $(65 \pm 12 \mu \mathrm{M})$ and CPS-368 $(104 \pm 30 \mu \mathrm{M})$ had somewhat higher $\mathrm{EC}_{50}$ values closer to that of menthol (Figure 1, 2 and table 1 ). Unexpectedly, the furanone derivatives (shown in Figure 3B ) did not activate TRPM8 at any tested concentrations (from $10 \mu \mathrm{M}$ to $10 \mu \mathrm{mM}$ ). Similarly, a monoterpenoid Citral was also found to be inactive (Figure 3B; and negative data not shown). 


\section{Activation mode}

For TRPM8, at least two different activation modes have been described: While the activation by menthol is independent of the intra- and extracellular calcium concentration and $\mathrm{pH}$, the structurally unrelated synthetic agonist icilin is only able to activate TRPM8 in the presence of calcium ions. Furthermore, TRPM8 activation by icilin is blocked by an acidic $\mathrm{pH}$ (35).

In order to further characterize the new agonists, we applied WS-5, CPS-125, CPS-368 and CPS-369 in the presence and absence of extracellular calcium. All five compounds robustly activated the channel in a nominally calcium-free solution as shown in Figure 2A. While the currents elicited by icilin were much higher in a calcium-containing solution, amplitudes elicited by WS- 5 or any of the CPS compounds varied little between both conditions (Table I). These results indicate that all five compounds activated TRPM8 through a $\mathrm{Ca}^{2+}$ independent mechanism. In addition, acidification of the applied solution to a $\mathrm{pH}$ of 6.1 did not markedly reduce currents elicited by WS-5, CPS125, CPS-368 or CPS-369, while icilin-evoked currents were significantly decreased (Figure 2B / Table I).

As icilin and menthol do not share the same activation mechanism, we sought to determine whether the maximal amplitudes elicited by both compounds differed in calcium-containing solutions (Figure 2C). Currents evoked by saturating concentrations of icilin $(100 \mu \mathrm{M})$ were higher by a factor of 2.1 compared to that of menthol $(10 \mathrm{mM})$. Interestingly, at nearly saturating concentrations $(1 \mathrm{mM})$, the menthol derivatives WS-5, CPS-125, CPS-368 and CPS369 also evoked roughly two fold higher amplitudes than menthol at $10 \mathrm{mM}$ (Table I). Thus, while activating TRPM8 through the same mechanism as menthol, both potency and efficacy of the derivatives were more comparable to that of icilin.

\section{Specificity of TRPM8 agonists}

A significant overlap in the pharmacology of several different TRP channels has been reported $(17,21,29,32)$. As specificity is highly relevant to the clinical value of a potential drug, we tested all compounds on the thermosensitive TRP channels TRPA1 as well as TRPV1-4 and compared their activity to that of known agonists of these channels.TRPA1 is activated by pungent chemicals such as cinnamaldehyde and mustard oil (36) and, as recently shown, by intracellular calcium (37). The control agonist icilin activated TRPA1 (Figure 4) as reported (21). In contrast, none of the CPS compounds elicited a response at $1 \mathrm{mM}$, a concentration that was nearly saturating for TRPM8 activation (Figure 4).

Similarly to TRPA1, TRPV1 is a receptor for nociceptive stimuli. Therefore, avoidance of TRPV1 activation is an important requirement for an analgesic drug. All compounds elicited only negligible currents at $1 \mathrm{mM}(<2 \%$ of the current evoked by $10 \mu \mathrm{M}$ capsaicin; Figure 4).

TRPV2 has a potential role in peripheral sensitization during inflammation, possibly in the transduction of pain hypersensitivity to high noxious temperature (38). Also at the TRPV2 receptor, none of the tested substances showed any activity when applied in $1 \mathrm{mM}$ concentrations (Figure 4), whereas the TRPV1-3 agonist 2APB (2-aminoethoxydiphenyl borate, $3 \mathrm{mM}$ ) was active (31).

Menthol has been demonstrated to activate TRPV3 in CHO and HEK293 cells (17, 39). Consistent with this report, we reported that menthol activates TRPV3 also in Xenopus oocytes (18). Yet, none of the CPS compounds induced a detectable TRPV3-mediated current (Figure 4), whereas the established agonist 2APB $(1 \mathrm{mM})$ was active (40).

Recently, TRPV4, a widely expressed member of the TRP-family has been implicated in nociception, and specifically in inflammatory and neuropathic pain $(41,42)$. Activation of this channel by the CPS compounds was also tested. None of the CPS-compounds activated the channel to a significant extent $(>10 \%$ of the PMA-evoked current, Figure 4), although it was activated by $10 \mu \mathrm{M}$ of the TRPV4 agonist PMA (phorbol 12-myristate 13-acetate) (43).

In addition to TRPM8, menthol is also a ligand for TRPA1. While the new compounds are no agonists for TRPA1, they still might be ligands with antagonistic properties. Therefore, we tested if the new compounds could block TRPA1 response to mustard oil and found that they were no blockers at $1 \mathrm{mM}$ concentrations. Also TRPV1 was not blocked by $1 \mathrm{mM}$ of any of the substances (data dot shown). Thus, the four tested compounds are not only potent agonists on TRPM8, but also selective with respect to other thermo-TRPs, in contrast to the two established TRPM8 agonists menthol and icilin. 
A

WS-5
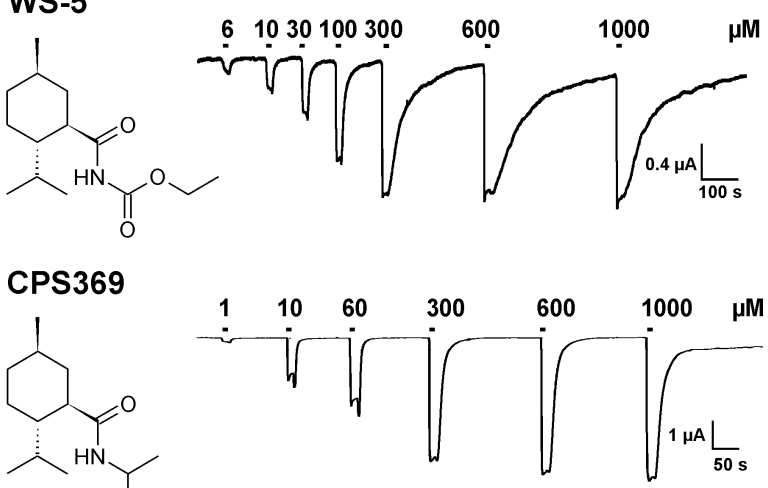
O
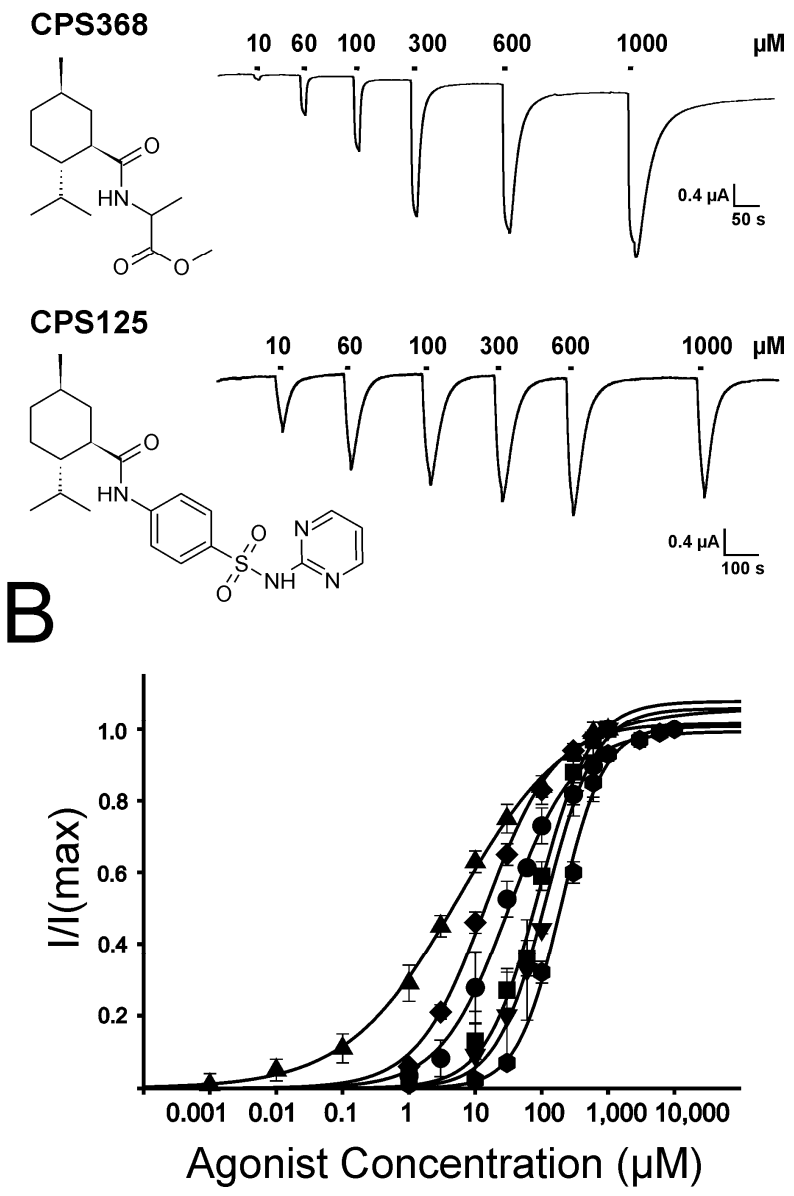

Figure 1: Activation of TRPM8 by different derivatives of (-)-menthol. (A) Chemical structure of the tested compounds and representative responses of individual oocytes expressing TRPM8 to WS-5, CPS-125, CPS-368 and CPS-369. (B) Concentration-response curves for inward currents evoked by WS-5 (tilted square), CPS-125 (circle), CPS-368 (downward triangle), CPS-369 (square), (-)-menthol (hexagon) and icilin (upward triangle) in Xenopus oocytes constructed of mean values of four to seven experiments fitted by the Hill equation. 


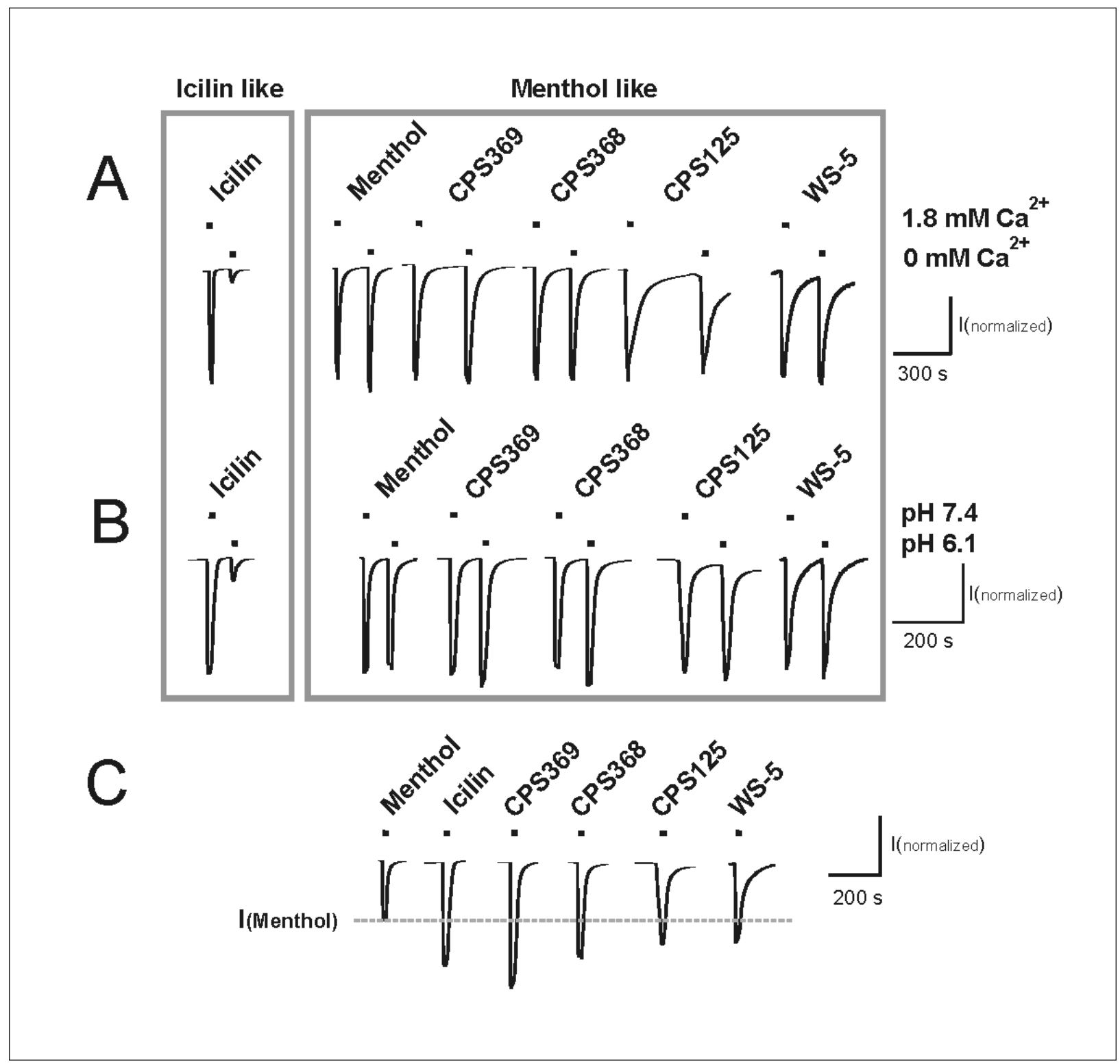

Figure 2. Biophysical characterization of the mode of activation of TRPM8 by the new agonists. (A) Activation of TRPM8 in the presence $(1.8 \mathrm{mM})$ and absence of extracellular calcium. While optimal concentrations of menthol $(10 \mathrm{mM})$ and derived compounds $(1 \mathrm{mM})$ show similar amplitudes under both conditions, icilin-evoked currents $(10 \mu \mathrm{M})$ are much reduced. To depict the effect of calcium, current amplitudes were normalized to the first response of the respective agonist in the presence of extracellular calcium. Measurements were from different oocytes. (B) Activation of TRPM8 at different $\mathrm{pH}$. Menthol and derived compounds induce similar current amplitudes at $\mathrm{pH} 6.1$ as at $\mathrm{pH} 7.4$, while icilin currents are much reduced at an acidic $\mathrm{pH}$. Amplitudes were normalized to the first response of the respective agonist at $\mathrm{pH} 7.4$. Measurements were from different oocytes. All experiments were conducted at room temperature $\left(\sim 23^{\circ} \mathrm{C}\right)$.

\section{DISCUSSION}

TRP channels are emerging as important targets for new therapeutics and pharmaceuticals due to their expression in sensory neurons; and many members of this family are implicated in the pruritus, pain and inflammatory pathways $(6,13)$. The idea of cooling an area of injury e.g. by cold compresses or application of the TRPM8 agonist menthol for pain relief has a long history. 


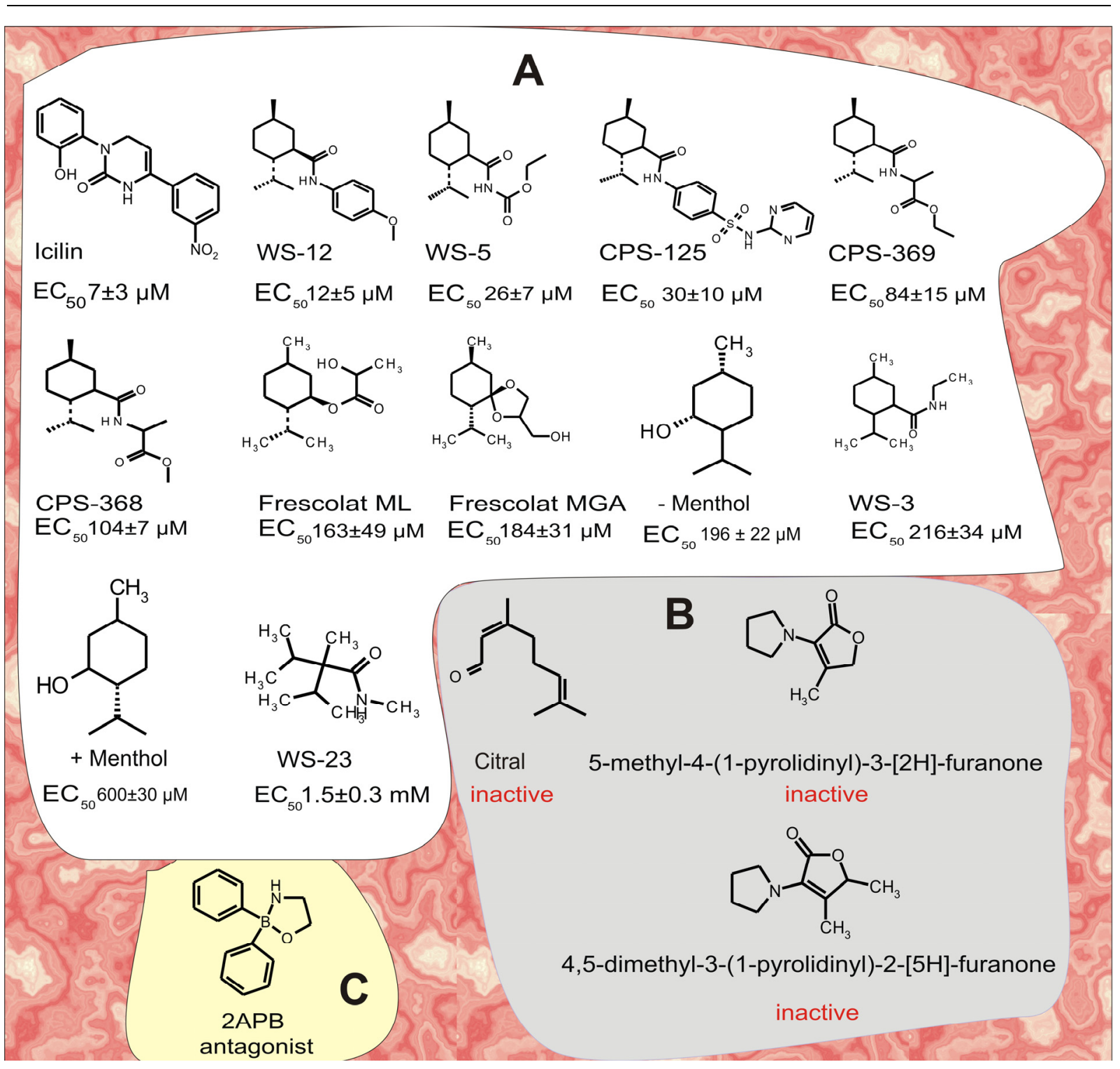

Figure 3. Structure activity relationship of TRPM8 ligands based upon potencies obtained from responses in oocyte expression system. Group (A) consists of menthol and menthol derivatives along with WS-23 which does not have structural features of menthol. Group (B) consists of virtually inactive substances, two of the furanone structures were developed with the claim that they are super-cooling agents. Group (C) shows 2APB which is a well known modulator of many TRP channels and effectively blocks TRPM8.

Proudfoot and colleagues (2006) demonstrated that TRPM8 activation results into central inhibition of nociceptive input (15), this highlighted a new approach to peripheral analgesia via targeting TRPM8. While this mechanism has been elucidated in principle using menthol and icilin, the limits of these drugs are obvious, since they also activate nociceptors like TRPV3 and TRPA1 $(17,18,44)$. Therefore, the development of specific TRPM8 agonists is of foremost interest both in basic research as well as in clinical therapeutics.
Recently we reported (18) selectivity of WS12 for TRPM8. This study obliged us to investigate whether other related structures have similar TRPM8 selectivity profile sparing other Thermo-TRPs. In addition we also investigated structures which are not related to menthol, particularly two furanone (Figure 3 group B) structures were of interest because they were developed with the claim to be the 'super cooling' agents and have received a lot of media hype. We report here that these compounds are totally inactive candidates for TRPM8 activation and 
bear little, if any, cooling efficacy. However, derivatives of menthol activate TRPM8 with an $\mathrm{EC}_{50}$ up to 10-fold lower than the parent compound and display a greatly enhanced selectivity for the target. In the light of the structural similarity of the TRP channels, the specificity for TRPM8 is an interesting finding as the bulky group attached in these CPS compounds which replaces the hydroxyl-group in menthol enhances affinity and efficacy for TRPM8 ion channels. These substituted groups seems to have abolished the activating ability of these substances for TRPV3 and TRPA1.
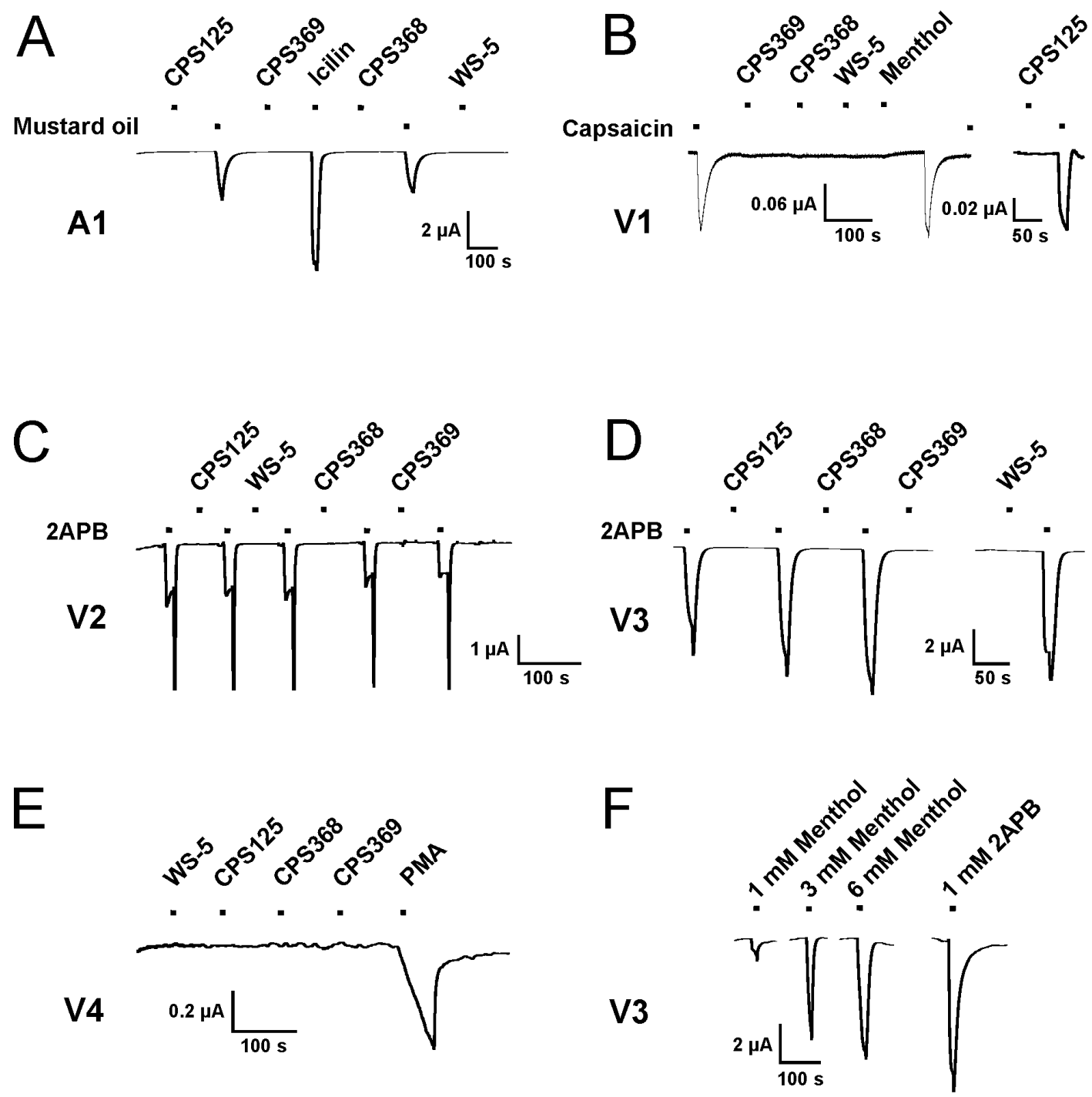

Figure 4. Testing of (-)-menthol derivatives for activation of different TRP channels expressed in Xenopus oocytes. WS-5, CPS-125, CPS-368 and CPS-369 were applied at a concentration of $1 \mathrm{mM}$, which is a saturating concentration on TRPM8. For measurements of TRPV1, 3 mM concentrations of WS-5, CPS-368, CPS-369 and $1 \mathrm{mM}$ of CPS-125 were applied. Responses were compared to those evoked by reference agonists for the respective receptors. The (-)menthol derivatives were tested for activation of TRPA1 in comparison to the agonist mustard oil (100 $\mu \mathrm{M})(\mathrm{A})$, on TRPV1 to $10 \mu \mathrm{M}$ (B, left) or $3 \mu \mathrm{M}$ capsaicin (B, right), on TRPV2 to $3 \mathrm{mM} 2 \mathrm{APB}$ (C), on TRPV3 to $1 \mathrm{mM} 2 \mathrm{APB}$ (D) and on TRPV4 to $10 \mu \mathrm{M}$ PMA (E). None of the (-)-menthol derivatives evoked currents $>5 \%-10 \%$ relative to the reference substances. In contrast to the specificity of the tested (-)-menthol derivatives, in higher concentrations (-) menthol itself and icilin are effective agonists for TRPV3 (F) or TRPA1 (A) respectively. None of the menthol derivatives evoked currents $>5 \%$ relative to the reference substances. In contrast to the specificity of the tested 


\begin{tabular}{|c|c|c|c|c|}
\hline \multirow[t]{2}{*}{ Substance } & \multirow{2}{*}{$\frac{\text { Response at pH } 6.1}{\text { Response at pH } 7.4}$} & \multirow{2}{*}{$\frac{\text { Response with } \mathrm{Ca}^{2+}}{\text { Response without } \mathrm{Ca}^{2+}}$} & \multirow{2}{*}{$\begin{array}{l}\text { Max. Efficacy } \\
\text { rel. to } 10 \mathrm{mM} \\
\text { - Menthol }\end{array}$} & \multirow[t]{2}{*}{$\mathrm{EC}_{50}$ in $\mu \mathrm{M}$} \\
\hline & & & & \\
\hline - Menthol & $0.99 \pm 0.008$ & $0.96 \pm 0.02$ & 1 & $196 \pm 22$ \\
\hline Icilin & $0.2 \pm 0.013^{* * *}$ & $20 \pm 1.30 * * *$ & $2.13 \pm 0.09$ & $7 \pm 3$ \\
\hline CPS-125 & $1.05 \pm 0.008$ & $0.97 \pm 0.05$ & $1.77 \pm 0.16$ & $32 \pm 6$ \\
\hline CPS-368 & $1.10 \pm 0.020$ & $0.99 \pm 0.03$ & $1.84 \pm 0.03$ & $104 \pm 30$ \\
\hline CPS-369 & $1.03 \pm 0.020$ & $1.02 \pm 0.03$ & $2.02 \pm 0.08$ & $65 \pm 12$ \\
\hline WS-5 & $1.03 \pm 0.023$ & $1.09 \pm 0.30$ & $1.48 \pm 0.13$ & $26 \pm 7$ \\
\hline WS-12 & $1.14 \pm 0.9$ & $1.00 \pm 0.02$ & $1.65 \pm 0.3$ & $12 \pm 5$ \\
\hline Frescolat ML & $1.01 \pm 0.008$ & $0.95 \pm 0.05$ & $1.00 \pm 0.3$ & $163 \pm 49$ \\
\hline Frescolat MGA & $1.02 \pm 0.020$ & $0.98 \pm 0.03$ & $0.70 \pm 0.13$ & $184 \pm 3$ \\
\hline WS-3 & $1.07 \pm 0.020$ & $1.00 \pm 0.03$ & $1.48 \pm 0.12$ & $216 \pm 34$ \\
\hline WS-23 & $1.06 \pm 0.023$ & $1.02 \pm 0.30$ & $0.25 \pm 0.01$ & $1500 \pm 300$ \\
\hline Coolact P & $1.11 \pm 0.9$ & $1.00 \pm 0.02$ & $0.20 \pm 0.03$ & $498 \pm 57$ \\
\hline
\end{tabular}

Table 1. Comparative potencies, efficacies and biophysical properties of TRPM 8 agonists . In Column 1 TRPM8 agonists are listed. Column 2 shows influence of extracellular calcium on TRPM8 activation. Column 3 shows influence of $\mathrm{pH}$ on TRPM8 activation. Column 4 shows comparative maximum amplitudes of TRPM mediated currents induced by different agonists. Amplitudes evoked by saturating concentrations of WS-5, WS-12, CPS-125, CPS-368, CPS-369 (1 mM), WS-3, WS-23, Frescolat ML, Frescolat MGA, Coolact $\mathrm{P}(10 \mathrm{mM})$ or icilin $(100 \mu \mathrm{M})$ were normalized to the responses to $10 \mathrm{mM}$ menthol. Column 5 shows potencies of TRPM8 agonists. Data are mean \pm SEM of six independent experiments.

Additionally hexacyclic ring structure also appears to be a structural requirement for robust TRPM8 activation, as depicted by WS-23 which activates TRPM8 but at high $\mathrm{mM}$ concentrations. Where as Citral (another monoterpene) is totally inactive. Interestingly, the diphenylborate (2APB) structure is an efficient antagonist of TRPM8 at $\mu \mathrm{M}$ concentrations $\left(\mathrm{IC}_{50}<100 \mu \mathrm{M}\right)$. All this indicates that for any potent ligand of TRPM8, hexacyclic rings are essential structural feature for efficient binding with TRPM8 channel proteins.

Recently, Bödding et al. (2007) also reported the activation of TRPM8 by CPS-369, but selectivity of CPS-369 for TRPM8 within the subgroup of Thermo-TRPs was not investigated (45). We also published activation and selectivity of CPS-369 in an abstract form (46).

Icilin contains hexacyclic aromatic rings in its structure but in chemical terms is not related to menthol. Additionally, icilin activates TRPM8 through a different mechanism. That is, activation of TRPM8 by icilin is dependent on the presence of calcium in extracellular solution and is affected by the prevailing $\mathrm{pH}$. As inflammatory conditions are associated with a $\mathrm{pH}$ drop in the tissue, this property could potentially limit the usefulness of icilin as an analgesic in an inflammatory environment or traumatic injury to the tissue. Icilin evokes currents of different maximal amplitudes as compared to menthol. It is not unexpected in the light of the profound differences in the activation mechanism of these two substances. However, it is significant to note that menthol derivatives, which use the $\mathrm{Ca}^{2+}$ independent mechanism as menthol, have larger maximal amplitudes than their parent compound. This may suggest that menthol is only a partial agonist for TRPM8. This hypothesis gets 
additional support from a recent finding (47) that icilin inhibits menthol activation of TRPM8. It is a well known pharmacological phenomenon that when a partial agonist is mixed with full agonist, the partial agonist acts as antagonist.

\section{CONCLUSION}

Taken as a whole, in the present investigation we were able to identify derivatives of menthol which activate TRPM8 with a higher potency and selectivity than menthol. Of the TRPM8 activators found to date, the new compounds are specific for TRPM8, and might be of importance for the development of new pharmacological agents as well as for characterization of TRPM8 function in different tissues of the body where it may not be acting as a temperature sensor like inner body organs and bone-marrow osteoblasts (48). Secondly, we could also show that hexacyclic rings attached to bulky side chains might be responsible for this enhanced selectivity and potency of TRPM8 ligands. Thirdly, it is also clear that pentacyclic structures like furanones are no agonists of TRPM8 and have little, if any, significance as cooling substances.

\section{STATEMENT OF NOVELTY}

The new compounds have an unmatched specificity for TRPM8 ion channels with additional display of high potency and efficacy. Thus these substances are better pharmacological tools for TRPM8 characterization then known compounds and it is suggested that these mentholderivates may serve as model substances for the development of TRPM8 ligands.

\section{ACKNOWLEDGEMENTS}

We thank Professor Edward T. Wei from University of California at Berkeley for generous gift of the test substances. The financial support to Dr. Sherkheli M.A. by IMPRS-CB, Research Excellence School of Bochum, DAAD and HECPakistan is highly appreciated.

\section{REFERENCES}

1. den Dekker E., Molin D. G., Breikers G., van Oerle R., Akkerman J. W., van Eys G. J., and Heemskerk J. W. Expression of transient receptor potential mRNA isoforms and $\mathrm{Ca}^{(2+)}$ influx in differentiating human stem cells and platelets. Biochim Biophys Acta 1539: 243-55, 2001.
2. Weick J. P., Johnson M. A., and Zhang S. C. Developmental regulation of human embryonic stem cell-derived neurons by calcium entry via transient receptor potential channels. Stem Cells 27: 2906-16, 2009.

3. Clapham D. E., Runnels L. W., and Strubing C. The TRP ion channel family. Nature Reviews Neuroscience 2: 387-396, 2001.

4. Montell C. The TRP superfamily of cation channels. Sci STKE 2005: re3, 2005.

5. Nilius B., Owsianik G., Voets T., and Peters J. A. Transient receptor potential cation channels in disease. Physiological Reviews 87: 165-217, 2007.

6. Levineand J. D. and Alessandri-Haber N. TRP channels: Targets for the relief of pain. Biochimica Et Biophysica Acta-Molecular Basis of Disease 1772: 989-1003, 2007.

7. McKemy D. D., Neuhausser W. M., and Julius D. Identification of a cold receptor reveals a general role for TRP channels in thermosensation. Nature 416: 52-8, 2002.

8. Bautista D. M., Siemens J., Glazer J. M., Tsuruda P. R., Basbaum A. I., Stucky C. L., Jordt S. E., and Julius D. The menthol receptor TRPM8 is the principal detector of environmental cold. Nature 448: 204-U11, 2007.

9. Colburn R. W., Lubin M. L., Stone D. J., Wang Y., Lawrence D., D'Andrea M. R., Brandt M. R., Liu Y., Flores C. M., and Qin N. Attenuated cold sensitivity in TRPM8 null mice. Neuron 54: 379-386, 2007.

10. Dhaka A., Murray A. N., Mathur J., Earley T. J., Petrus M. J., and Patapoutian A. TRPM8 is required for cold sensation in mice. Neuron 54: 371-8, 2007.

11. Walker K. M., Urban L., Medhurst S. J., Patel S., Panesar M., Fox A. J., and McIntyre P. The VR1 antagonist capsazepine reverses mechanical hyperalgesia in models of inflammatory and neuropathic pain. $J$ Pharmacol Exp Ther 304: 56-62, 2003.

12. Stander S., Moormann C., Schumacher M., Buddenkotte J., Artuc M., Shpacovitch V., Brzoska T., Lippert U., Henz B. M., Luger T. A., Metze D., and Steinhoff M. Expression of vanilloid receptor subtype 1 in cutaneous sensory nerve fibers, mast cells, and epithelial cells of appendage structures. Exp Dermatol 13: 129-39 (2004).

13. M. Steinhoffand T. Biro. A TR(I)P to pruritus research: role of TRPV3 in inflammation and itch. J Invest Dermatol 129: 531-5, 2009.

14. Szallasiand A. and Appendino G. Vanilloid receptor TRPV1 antagonists as the next generation of painkillers. Are we putting the cart before the horse? J Med Chem 47: 2717 23, 2004.

15. Proudfoot C. J., Garry E. M., Cottrell D. F., Rosie R., Anderson H., Robertson D. C., 
Fleetwood-Walker S. M., and Mitchell R. Analgesia mediated by the TRPM8 cold receptor in chronic neuropathic pain. Curr Biol 16: 1591-605, 2006.

16. Bini G., Cruccu G., Hagbarth K. E., Schady W., and Torebjork E. Analgesic effect of vibration and cooling on pain induced by intraneural electrical stimulation. Pain 18: 239-48, 1984.

17. Macpherson L. J., Hwang S. W., Miyamoto T., Dubin A. E., Patapoutian A., and Story G. M. More than cool: Promiscuous relationships of menthol and other sensory compounds. Molecular and Cellular Neuroscience 32: 335-343, 2006.

18. Sherkheli M. A., Gisselmann G., Vogt-Eisele A.K, Doerner. J.F, and Hatt H. Menthol derivative WS-12 selectively activates transient receptor potential melastatin-8 (TRPM8) ion channels. Pak J Pharm Sci 21: 370-8, 2008.

19. Sherkheli M. A. Trip through the pharmacology of hot- and cold sensing TRP ion channels: a hope for better painkillers and anti-inflammatory drugs, ISBN\# 978-3639-24933-0 VDM Verlag, Saarbruecken, Germany, 2010.

20. Hu H. Z., Xiao R., Wang C., Gao N., Colton C. K., Wood J. D., and Zhu M. X. Potentiation of TRPV3 channel function by unsaturated fatty acids. J Cell Physiol 208: 201-12, 2006.

21. Story G. M., Peier A. M., Reeve A. J., Eid S. R., Mosbacher J., Hricik T. R., Earley T. J., Hergarden A. C., Andersson D. A., Hwang S. W., McIntyre P., Jegla T., Bevan S., and Patapoutian A. ANKTM1, a TRP-like channel expressed in nociceptive neurons, is activated by cold temperatures. Cell 112: 819-829, 2003.

22. Wasner J. S. G., Binder A., and Baron R. Topical menthol - a huamn model for cold pain by activation and sensitization of $\mathrm{C}$ nociceptors. Brain 127: 1159-1171, 2004.

23. Andersson D. A., Chase H. W., and Bevan S. TRPM8 activation by menthol, icilin, and cold is differentially modulated by intracellular pH. J Neurosci 24: 5364-9, 2004.

24. Kuhn F. J., Kuhn C., and Luckhoff A. Inhibition of TRPM8 by icilin distinct from desensitization induced by menthol and menthol derivatives. J Biol Chem, 2008.

25. Tsavaler L., Shapero M. H., Morkowski S., and Laus R. Trp-p8, a novel prostate-specific gene, is up-regulated in prostate cancer and other malignancies and shares high homology with transient receptor potential calcium channel proteins. Cancer Res 61: 3760-9, 2001.

26. Yamamura H., Ugawa S., Ueda T., Morita A., and Shimada S. TRPM8 activation suppresses cellular viability in human melanoma. American Journal of Physiology-Cell Physiology 295: C296-C301, 2008.

27. Li Q., Wang X., Yang Z., Wang B., and Li S. Menthol induces cell death via the TRPM8 channel in the human bladder cancer cell line T24. Oncology 77: 335-41, 2009.

28. Watson H. R., Hems R., Rowsell D. G., and Spring D. J. New Compounds with Menthol Cooling Effect. Journal of the Society of Cosmetic Chemists 29: 185-200, 1978.

29. Behrendt H. J., Germann T., Gillen C., Hatt H., and Jostock R. Characterization of the mouse cold-menthol receptor TRPM8 and vanilloid receptor type-1 VR1 using a fluorometric imaging plate reader (FLIPR) assay. Br J Pharmacol 141: 737-45, 2004.

30. Erman M. Progress in physiological cooling agents. Perfumes and Flavorists 29: 34-50, 2004.

31. Hu H. Z., Gu Q. H., Wang C. B., Colton C. K., Tang J. S., Kinoshita-Kawada M., Lee L. Y., Wood J. D., and Zhu M. X. 2aminoethoxydiphenyl borate is a common activator of TRPV1, TRPV2, and TRPV3. Journal of Biological Chemistry 279: 3574135748, 2004.

32. Weil A., Moore S. E., Waite N. J., Randall A., and Gunthorpe M. J. Conservation of functional and pharmacological properties in the distantly related temperature sensors TRVP1 and TRPM8. Mol Pharmacol 68: 518-27, 2005.

33. Villmann C., Bull L., and Hollmann M. Kainate binding proteins possess functional ion channel domains. J Neurosci 17: 7634-43, 1997.

34. Sherkheli M. A., Benecke H., Doerner J. F., Kletke O., Vogt-Eisele A. K., Gisselmann G., and Hatt $\mathrm{H}$. Monoterpenoids induce agonistspecific desensitization of transient receptor potential vanilloid-3 (TRPV3) ion channels. $J$ Pharm Pharm Sci 12: 116-28, 2009.

35. Chuang H. H., Neuhausser W. M., and Julius D. The super-cooling agent icilin reveals a mechanism of coincidence detection by a temperature-sensitive TRP channel. Neuron 43: 859-869, 2004.

36. Clapham D. E. TRP channels as cellular sensors. Nature 426: 517-524, 2003.

37. Doerner J. F., Gisselmann G., Hatt H., and Wetzel C. H. Transient receptor potential channel a1 is directly gated by calcium ions. Journal of Biological Chemistry 282: 1318013189, 2007.

38. Shimosato G., Amaya F., Ueda M., Tanaka Y., Decosterd I., and Tanaka M. Peripheral inflammation induces up-regulation of TRPV2 expression in rat DRG. Pain 119: 225-232, 2005. 
39. Vogt-Eisele A. K., Weber K., Sherkheli M. A., Vielhaber G., Panten J., Gisselmann G., and Hatt $H$. Monoterpenoid agonists of TRPV3. Br J Pharmacol 151: 530-40, 2007.

40. Chung M. K., Lee H., Mizuno A., Suzuki M., and Caterina M. J. 2-aminoethoxydiphenyl borate activates and sensitizes the heat-gated ion channel TRPV3. Journal of Neuroscience 24: 5177-5182, 2004.

41. Suzuki M., Mizuno A., Kodaira K., and Imai M. Impaired pressure sensation in mice lacking TRPV4. J Biol Chem 278: 22664-8, 2003.

42. Alessandri-Haber N., Dina O. A., Yeh J. J., Parada C. A., Reichling D. B., and. Levine J. D. Transient receptor potential vanilloid 4 is essential in chemotherapy-induced neuropathic pain in the rat. $J$ Neurosci 24: 4444-52, 2004.

43. Watanabe H., Davis J. B., Smart D., Jerman J. C., Smith G. D., Hayes P., Vriens J., Cairns W., Wissenbach U., Prenen J., Flockerzi V., Droogmans G., Benham C. D., and Nilius B. Activation of TRPV4 channels (hVRL2/mTRP12) by phorbol derivatives. J Biol Chem 277: 13569-77, 2002.
44. Karashima Y., Damann N., Prenen J., Talavera K., Segal A., Voets T., and Nilius B. Bimodal action of menthol on the transient receptor potential channel TRPA1. J Neurosci 27: 9874-84, 2007.

45. Bodding M., Wissenbach U., and Flockerzi V. Characterisation of TRPM8 as a pharmacophore receptor. Cell Calcium 42: 618-628, 2007.

46. Sherkheli M. A., Gisselmann G., Mitchell R., Vogt-Eisele A-K, and Hatt H. Selective TRPM8 agonists: A novel group of neurophathic analgesics. Febs Journal 274: 232-232, 2007.

47. Kuhn F. J., Kuhn C., and Luckhoff A. Inhibition of TRPM8 by Icilin Distinct from Desensitization Induced by Menthol and Menthol Derivatives. J Biol Chem 284: 410211, 2009.

48. Abed E., Labelle D., Martineau C., Loghin A., and Moreau R. Expression of transient receptor potential (TRP) channels in human and murine osteoblast-like cells. $\mathrm{Mol} \mathrm{Membr}$ Biol 1-13, 2008. 